\title{
Práticas de leitura e compreensão para o desempenho do aluno surdo no ensino regular
}

Lucineide Machado Pinheiro*

\section{Resumo}

A leitura é fundamental para a formação dos alunos, é por meio dela que se dá a abordagem dos conteúdos escolares. Por isso, é preciso ensinar os alunos a lerem com competência, para que tenham um desempenho escolar satisfatório. Constata-se que as escolas não têm oferecido aos alunos, e entre eles, os surdos oralizados, práticas de leitura significativas, provocando assim, um baixo desempenho e um quadro de fracasso escolar. De forma contrária, práticas de leitura e compreensão desenvolvidas por profissionais da saúde em núcleos ou clínicas fonoaudiológicas, relatadas por vários autores, tem contribuído para minimizar a problemática que o ensino de leitura incipiente provoca na vida escolar desses alunos. Diante desse contexto, este estudo teve como objetivo, investigar a contribuição das práticas de leitura e compreensão de texto desenvolvidas por profissionais da saúde, para o desempenho do aluno surdo oralizado inserido no ensino regular. Trata-se de um estudo de caso, em que se utilizou como procedimento para coleta de dados, a observação na escola, na qual o aluno surdo encontra-se matriculado, e no Núcleo de Atuação Interdisciplinar de Audição, Linguagem e Educação (NAIALE), onde ele participa do atendimento voltado às dificuldades de leitura e compreensão. Os resultados demonstraram que as práticas de leitura e compreensão desenvolvidas no NAIALE, contribuem para um desempenho escolar satisfatório, pois atendem as especificidades de aprendizagem dos alunos surdos oralizados.

Palavras-chave: Desempenho escolar; Leitura; Língua portuguesa; Surdos.

* Professora do Instituto Federal de Educação, Ciência e Tecnologia de São Paulo (IFSP). Canindé, Sao Paulo.

Revista Educação Especial | v. 26 | n. 45, | p. 193-208 | jan./abr. 2013

Santa Maria

Disponível em: <http://www.ufsm.br/revistaeducacaoespecial> 


\title{
Practice reading and understanding the performance of deaf students in regular schools
}

\begin{abstract}
Reading is fundamental to the development of students, is through it that takes the approach of classroom content. Therefore, we must teach students to read with competence, so they have a satisfactory academic performance. It appears that schools have not offered to students, and among them, the deaf who use oral language, reading practices significant, thus causing a poor performance and a framework for school failure. Conversely, practices of reading and understanding developed by health professionals in speech therapy centers or clinics, reported by several authors, has helped to minimize the problems that the teaching of reading incipient causes of these students in school life. Given this context, this study aimed to investigate the contribution of the practices of reading and text comprehension developed by healthcare professionals for the performance of deaf students in regular education oralizado inserted. This is a case study, which used as a procedure for data collection, observation in the school in which the student is enrolled deaf, and the Center for Interdisciplinary Practice Hearing, Language and Education (NAIALE), where he participates in services focused on reading and comprehension difficulties. The results showed that the practices of reading and understanding developed in NAIALE contribute to a satisfactory academic performance as meet the specific learning of deaf students who use oral language.
\end{abstract}

Keywords: School performance; Reading; Portuguese; Deaf.

Introdução

Desempenho escolar consiste na realização das atividades e tarefas escolares pelo aluno, de forma eficaz, para alcançar o objetivo principal, que é o aprendizado. Para alcançar esse objetivo, muitos são os fatores que corroboram, como por exemplo, as características da escola, da família e do aluno (OLIVEIRA; BORUCHOVITCH; SANTOS, 2008).

Em relação às características da escola, há que se considerar a infraestrutura física, os materiais didáticos que a escola possui e os profissionais que atuam nela. Tratando-se da família, os aspectos a serem considerados dizem respeito ao nível de escolarização dos pais e sua influência na aprendizagem dos filhos. Por último, no que concerne às 
características do aluno, o ideal é que ele apresente domínio de leitura suficiente, a fim de compreender os textos escritos das diferentes disciplinas escolares, pois "quanto melhor for à compreensão em leitura dos estudantes, maior será o seu desempenho acadêmico" (OLIVEIRA; BORUCHOVITCH; SANTOS, 2008, p. 534).

Nesse sentido, a escola precisa ensinar aos alunos a lerem, uma vez que, é por meio da leitura, que se dará a abordagem do conteúdo das diversas disciplinas escolares. Por esse motivo, Cagliari (1990) afirma que aprender a ler é mais importante do que saber escrever. Para ele, ler é a atividade fundamental desenvolvida pela escola para a formação dos alunos.

Em relação à educação dos surdos, o que se observa, nas escolas, é que o ensino de leitura não tem sido significativo. As crianças surdas não têm interagido, de maneira funcional com a língua escrita, e nem tão pouco construído conhecimentos necessários para todas as etapas da sua aprendizagem (PEREIRA, 2009). Góes (1996) aponta que isso ocorre, porque as escolas têm oferecido experiências de leitura restritas e descontextualizadas para os alunos surdos, baseando-se na valorização do léxico, com foco nas regras gramaticais e no ensino de vocábulos isolados; o que faz com que, apresentem um baixo desempenho e um quadro de fracasso escolar.

O ensino da leitura que supervaloriza o léxico e a decodificação das palavras é decorrente da crença de que ler consiste apenas em conhecer o significado das palavras, a fim de se ter um léxico amplo, necessário para a compreensão do texto. Assim, por esse viés, as causas das dificuldades de leitura dos alunos surdos passam a ser atribuídas apenas ao fato de terem um léxico restrito (PEREIRA, 2009).

Fato é que os surdos apresentam um léxico restrito, dificuldades na leitura e na polissemia da língua. Porém, a dificuldade do surdo na compreensão textual, não decorre apenas dessas questões, mas também, de outras vinculadas ao acesso à língua e aos processos de ensino que desconsideram as especificidades dos alunos surdos (BOTELHO, 2005).

Botelho (2005) comenta que, ter uma língua desenvolvida e plenamente à disposição é uma das condições de possibilidades para aprender a ler com competência. Em sua investigação com surdos oralizados, observou que aqueles que tinham mais acesso a língua oral, eram os que conseguiam discutir sobre as estórias contidas nos livros e revistas. A autora comenta ainda, que o fato de ter uma língua à disposição, não elimina suas dificuldades em leitura e compreensão, sendo necessário, portanto, um ensino de leitura diferenciado, de modo a atender as suas dificuldades e especificidades. 
Diante disso, experiências de práticas de leitura e compreensão de texto, desenvolvidas por profissionais da saúde, com alunos surdos oralizados, em núcleos ou clínicas fonoaudiológicas, que lograram êxito, foram descritas por autores como Mendes e Novaes (2003); Trenche e Balieiro (2004). Tais experiências, tem se apresentado como uma alternativa viável para minimizar os impactos que a problemática das práticas de leitura incipientes desenvolvidas nas escolas de ensino regular, provoca na escolarização desses alunos.

Por isso, aventou-se a hipótese de que as práticas de leitura e compreensão de texto desenvolvidas por profissionais da saúde em clínicas fonoaudiológicas corroboram para o desempenho escolar do aluno surdo, pois, segundo Sacaloski (2004), a atuação pedagógica deve estar articulada com as ações desenvolvidas pelos profissionais dos sistemas de saúde.

Assim, este trabalho teve como objetivo, investigar a contribuição das práticas de leitura e compreensão de texto desenvolvidas por profissionais da saúde, para o desempenho do aluno surdo oralizado inserido no ensino regular.

\section{Referencial teórico}

A leitura é um processo interativo ente o leitor e o texto. Nesse processo, faz-se necessário que o leitor domine as habilidades de decodificação dos grafemas e compreenda o texto escrito por meio de procedimentos e capacidades (SOLÉ, 2009).

A decodificação dos grafemas foi considerada, até o início do século passado, como suficiente para o processo de leitura (ROJO, 2009). Mas, na segunda metade do século $\mathrm{XX}$, as pesquisas em torno do ato de ler, demonstraram que, para além das habilidades de decodificação, o leitor deve estabelecer objetivos diante de um texto. Esses, por sua vez, determinam os procedimentos e as capacidades envolvidas no ato de ler (ROJO, 2009; SOLÉ, 2009).

"Os procedimentos de leitura são os rituais que envolvem as práticas de leitura, como ler da esquerda para a direita, de cima para baixo e folhear um livro" (ROJO, 2009, p. 75). Segundo Solé (2009) e Rojo (2009), os três principais procedimentos de aprendizagem da leitura são: Bottom-up ou ascendente, que parte da menor unidade (sílaba) para a maior unidade (texto) em um processo linear e hierárquico que conduz à compreensão do texto; Top-down ou descendente, que ocorre quando utilizamos nossos conhecimentos prévios, realizamos inferências e elaboramos hipóteses para tentar entender o texto e Interativo, no qual o texto - sua forma e conteúdo - 
e o leitor - seus conhecimentos prévios e suas expectativas - interveem para a compreensão da linguagem escrita. Já as capacidades envolvidas no ato de ler, podem ser perceptuais, discursivas e linguísticas. Algumas delas são também denominadas de estratégias de leitura cognitivas e metacognitivas.

Embora tenhamos avançado no entendimento do significado da leitura, no âmbito escolar, ela continua a ensinar, valorizar e cobrar apenas o procedimento de leitura Bottom-up ou ascendente (ROJO, 2009). Entretanto, de acordo com Solé (2009), o principal problema do ensino de leitura nas escolas não se restringe apenas ao procedimento utilizado, mas ao significado que a instituição escolar possui sobre o que é leitura, da forma como os professores avaliam a leitura dos alunos e da importância, ou não, que ela ocupa nos projetos pedagógicos escolares.

As atividades de leitura mais frequentes nas escolas, que refletem a concepção adotada sobre o ato de ler, são, por exemplo, a decodificação de um texto por meio da leitura individual silenciosa, a leitura em grupo em voz alta, a recitação de um jogral e a declamação de uma poesia (ROJO, 2009). É por meio dessas atividades que os professores avaliam a "compreensão" leitora da criança. No entanto, o que, de fato, a escola pretende, nesse sentido, é que "os alunos leiam com clareza, rapidez, fluência e correção, pronunciando adequadamente, respeitando as normas de pontuação e com a entonação requerida" (SOLÉ, 2009, p. 98).

$\mathrm{Na}$ educação dos surdos, durante muito tempo, apenas a decodificação das palavras foi valorizada como condição única para atingir a compreensão. Segundo Pereira (2009, p. 25-27), um dos fatores que contribuiu para que isso acontecesse, foi o fato de o ensino da leitura ter dado muita "ênfase na palavra, associada ao pouco conhecimento do português por parte do aluno, o que provocou uma supervalorização do léxico na educação dos surdos".

Lemos (2007), destaca que o conhecimento do vocabulário é necessário para a leitura. Porém, enfatiza que, o mais importante é a depreensão do conteúdo e da significação da palavra em um determinado contexto por meio do texto.

A esse respeito, Pereira (2009) comenta que, pesquisas empenhadas em avaliarem a compreensão leitora de alunos surdos, quando o foco do ensino da leitura é o texto, ao invés de vocábulos e unidades isoladas, demonstraram um desempenho significativo. Isso contribuiu para que esses alunos desenvolvessem habilidades de leitura e também para uma mudança na concepção da escola acerca da leitura para eles. 
O principal desafio do ensino da leitura na escola deveria ser o de fazer com que os alunos se tornassem leitores competentes, de forma significativa, a fim de que apreendessem os significados dos conteúdos escolares por meio da leitura dos textos e materiais didáticos, e também, para que pudessem participar, de maneira efetiva, de uma sociedade cada vez mais letrada (SOLÉ, 2009).

\section{Objetivo}

O presente estudo teve como objetivo, investigar a contribuição das práticas de leitura e compreensão de texto desenvolvidas por profissionais da saúde, para o desempenho do aluno surdo oralizado inserido no ensino regular.

\section{Metodologia}

Participou deste estudo um aluno surdo oralizado, de nome fictício Pedro, que tem oito anos de idade e está matriculado no Ensino Fundamental em uma escola da rede pública no município de São Paulo. Ele apresenta perda auditiva neurossensorial de grau profundo bilateral, de causa desconhecida, comunica-se pela fala e eventualmente, por meio da Língua Brasileira de Sinais (LIBRAS). A perda auditiva foi diagnosticada aos dois anos e seis meses de idade, quando começou a utilizar o Aparelho de Amplificação Sonora Individual (AASI) e a receber atendimento no ambulatório de Audiologia Educacional de uma Universidade em São Paulo. Com seis anos de idade passou a frequentar o NAIALE, após encaminhamento feito pela equipe desses ambulatórios, responsáveis pelo atendimento voltado ao aproveitamento da audição e aquisição da fala.

O NAIALE oferece atendimento voltado às dificuldades específicas de leitura e compreensão de escolares surdos do Ensino Fundamental da rede pública estadual, por meio de encontros semanais, nos quais são utilizadas estratégias que atendem as especificidades de aprendizagem desses alunos. Essas estratégias contribuem para minimizar as dificuldades de leitura e compreensão, favorecendo a construção do significado.

Os profissionais que prestam atendimento no NAIALE são alunas do curso de graduação em Fonoaudiologia de uma Universidade em São Paulo, sob a orientação de uma pedagoga especializada em educação de surdos. Cada profissional atende entre uma a três crianças em cada encontro de leitura e compreensão. 
Os dados foram coletados por meio da observação dos atendimentos no NAIALE, e por meio da observação das aulas de Língua Portuguesa, na sala de aula do ensino regular, na qual o aluno surdo se encontrava matriculado, durante os meses de agosto a novembro de 2011. Os dados foram transformados em um diário de campo, onde foram selecionadas as informações mais importantes sobre os comportamentos observáveis e, submetidos à análise qualitativa, por meio do desempenho escolar do aluno surdo.

\section{Resultados}

A partir do objetivo deste estudo, selecionou-se para análise, um episódio em cada campo empírico, a saber: a escola e o NAIALE.

\section{$1^{0}$. Episódio - Leitura e compreensão de texto na escola.}

Ao chegar à sala de aula, a professora Joana ${ }^{1}$ solicitou aos alunos que escolhessem algum livro que estava na estante da sala, para fazerem uma leitura. Os alunos escolheram os livros e começaram a ler. Alguns leram sozinhos, outros em dupla. Pedro também escolheu um livro e sentou-se ao lado de uma colega chamada Sara.

O livro escolhido por Pedro continha muitas ilustrações e frases curtas. Durante a leitura, observei que eles associavam a ilustração às palavras que liam. Quando Pedro não compreendia alguma palavra, Sara explicava o significado.

Depois disso, Joana solicitou que os alunos guardassem os livros e entregou-lhes um texto mimeografado, intitulado: "O trem das águas", do autor Fernando Vilela, para a aula de Português. Esse texto conta a história de uma cobra gigante chamada Gil, que vive na Floresta Amazônica, lugar de árvores altas, onde os animais podem se esconder. Cobra Gil mora em um buraco e frequentemente acorda a noite para passear. Devido o seu tamanho, os animais pedem para ir junto, nas suas costas. Cobra Gil leva então, vários bichos, entre eles, os vaga-lumes. Por isso, quando os pescadores os vê passando a noite, pensam que é um monstro e gritam assustados: "Fujam! Fujam todos! Vem chegando o trem da assombração com a cabeça de fogo!".

Joana leu esse texto em voz alta com os alunos. Neste momento, Pedro não acompanhou a leitura, pois, estava distraído com a agitação dos colegas. Por isso, logo que terminou de ler o texto com a classe, ela o chamou para que ele o lesse. Pedro se levantou, dirigiu-se até a mesa dela 
e, em pé, oralizou-o. Em seguida, Joana parabenizou-o e pediu que voltasse ao seu lugar. Dando sequência a aula, Joana escreveu no quadro, um exercício sobre o texto e pediu que os alunos o copiassem e respondessem no caderno. Pedro abriu o caderno, copiou as questões do exercício e as respondeu. Segue abaixo as questões do exercício aplicadas por Joana.

\section{Questões:}

1) Esse texto se passa:

a) No Rio de Janeiro

b) Na Floresta Amazônica

c) No Paraná

2) Como eram as árvores:
a) Altas
b) Baixas
c) Médias
3) Quem morava no buraco?
a) A cobra
b) O tatu
c) A onça
4) O nome da cobra era:

a) Paula

b) Gil

c) Odet

5) Complete:

a) Saía do seu buraco todo o corpo e dava um tão comprido.

b) E cobra Gil, cansada de dormir, saía para dar seu

c) A cobra Gil saía à noite para 
6) Responda:

a) Quem cobra Gil levava?

b) Quem dizia, fujam! Fujam!

c) Por que a chamavam de trem da assombração?

Durante a resolução, Pedro localizou com facilidade as respostas das questões de número 1 a 5 . Na questão de número 6 , conseguiu responder as letras "a" e "b". Já na letra "c", apresentou dificuldade, não conseguiu responder sozinho e pediu ajuda aos colegas.

$2^{\circ}$ Episódio - Leitura e compreensão de texto no NAIALE.

Pedro e sua colega Ana, ao chegarem ao NAIALE, cumprimentaram a terapeuta Clarice, que Ihes apresentou o livro "Ninguém gosta de mim", que iriam ler e estudar, começando naquele dia e continuando nas próximas semanas. O livro conta a história de um cachorro cujo nome é Coquinho, que vai morar em outro lugar e, fica entediado por não ter nada para fazer e nem amigos para brincar.

Quando Pedro e Ana viram o livro, ficaram felizes e logo começaram a lê-lo, ao mesmo tempo, em voz alta e de forma muito rápida. Assim que concluíram, responderam:

Pronto! - mostrando que tinham terminado de ler o livro.

Em seguida, Clarice explicou que deveríamos ler o texto pausadamente, procurando entender o significado do texto e formulou perguntas.

Clarice: Quem falou ninguém gosta de mim?

Pedro e Ana: O cachorro.

Clarice: Qual o título do livro?

Ana: Ninguém gosta de mim.

Clarice: Qual o nome do cachorro?

Pedro e Ana: Coquinho

Clarice: Por que Coquinho estava entediado?

Pedro e Ana recorreram ao texto e leram o trecho que continha a palavra entediado, mas não conseguiram encontrar a resposta.

Revista Educação Especial | v. 26 | n. 45, | p. 193-208 | jan./abr. 2013

Santa Maria

Disponível em: <http://www.ufsm.br/revistaeducacaoespecial> 
Clarice explicou-Ihes que Coquinho estava entediado porque foi morar em outro lugar e não tinha amigos para brincar. Nesse momento, ela explicou que nascemos em lugares diferentes. Para melhorar a compreensão, utilizou recursos como papel sulfite e lápis de cor para demonstrar que podemos ser naturais de vários estados brasileiros. Escreveu em letras grandes as palavras: CEARÁ, BAHIA e SÃO PAULO, pois seus pais eram oriundos desses estados. Explicou que moramos em São Paulo, mas nem todos que estavam ali na sala tinham nascido em São Paulo. Clarice perguntou a Pedro e Ana se, caso mudassem de lugar, eles ficariam tristes ou chorariam. Pedro respondeu que não choraria; Ana, disse que sim.

No primeiro momento da história, utilizando a pergunta inicial - Por que Coquinho esta entediado? - Clarice relacionou a situação que Coquinho estava vivenciando no texto com situações da vida real, e comentou que, às vezes, nós também ficamos entediados. A partir disso, ela explicou-lhes que entediado significa aborrecido por não ter nada para fazer. No caso de Coquinho, significava que ele não tinha nada para fazer, nem amigos para brincar, porque tinha ido morar em outro lugar e ainda não conhecia ninguém.

Dando sequência à história, Coquinho foi procurar amigos e encontrou três gatos. O gato ficou olhando para Coquinho.

\section{Clarice: O gato foi brincar com Coquinho?}

Pedro e Ana: Não.

Eles responderam corretamente, pois, na história, nenhum animal quis brincar com Coquinho, nem os gatos, nem os coelhos. Depois disso, Clarice percebeu que o tempo havia esgotado e explicou-lhes que continuariam a história de Coquinho na próxima aula. Os alunos guardaram o livro no armário e se despediram de Clarice.

\section{Discussão}

Percebeu-se, em ambos os episódios, que Pedro utilizava procedimentos de leitura, como: folhear o livro, ler da direita para a esquerda, ler em voz alta ou silenciosamente e, também, associava frases curtas e palavras conhecidas às ilustrações do texto.

No episódio da escola, observaram-se dois momentos, um livre, no qual os alunos leram os livros sozinhos e outro direcionado, quando a professora leu o texto em voz alta com os alunos. Em ambos, evidenciouse que o procedimento de leitura adotado foi o Bottom up, ou ascendente, no qual apenas a decodificação do texto foi valorizada, sem que houvesse 
interferência da professora. A esse respeito, Solé (2009) comenta que existe uma série de outras estratégias que poderiam ter sido utilizadas antes, durante e após a leitura para ensinar os alunos a lerem e a compreenderem os textos, as quais, não foram observadas na prática de Joana.

No momento de leitura direcionada, chamou-nos a atenção o fato da professora ter chamado Pedro para que lesse o texto, e ao invés disso, ele apenas decodificou, não havendo nenhuma interferência por parte dela em seguida; o que não nos permite afirmar que ele tenha compreendido o texto. Segundo Paccini (2007), o fato de pronunciar todas as palavras de um texto, de maneira corrente, não significa dizer que o aluno surdo tenha alcançado a compreensão.

Em relação aos questionários aplicados por Joana, para fins de análise, optou-se por utilizar a classificação existente entre perguntas e respostas, propostas por Solé (2009); a explicitação de Pereira (2009) para perguntas de múltipla escolha; e a de Colomer e Camps (2002), para as questões de preencher espaços vazios.

Segundo Solé (2009), as perguntas e as respostas que podem surgir, a partir de um texto, são classificadas como perguntas de resposta literal - aquelas em que a resposta se encontra facilmente no texto; perguntas para pensar e buscar - aquelas cuja resposta precisa ser deduzida a partir de relações que o leitor estabelece no texto e também por meio das inferências; e perguntas de elaboração pessoal - aquelas que têm o texto como referencial, mas cuja resposta não se encontra no texto, precisando, assim, que o leitor disponha de outros tipos de conhecimento.

De acordo com a classificação acima, constatou-se que as questões de no. 1 a 4 do exercício aplicado por Joana são de múltipla escolha e permitiram que a resposta fosse facilmente encontrada no texto. Na questão de no. 1, Pedro demonstrou ter entendido que a expressão esse texto se passa, significa onde, e na questão de no. 2, que a palavra como se referia à forma da árvore. A questão 5 exigia que os alunos completassem os espaços em branco. Segundo Colomer e Camps (2002), esse tipo de questão é uma estratégia de leitura utilizada como forma de antecipar as ideias do texto. $\mathrm{Na}$ questão 6, Pedro conseguiu responder as letras "a" e "b". Para isso, ele precisou saber que, no texto, o interrogativo quem se referia aos animais e aos pescadores. Já na letra "c", a qual Pedro apresentou dificuldade, é considerada de interpretação de texto, ou seja, pergunta para pensar e buscar.

A forma como essas questões foram elaboradas e as respostas de Pedro nos permitem relacionar as contribuições das práticas desenvolvidas 
no NAIALE com o seu desempenho escolar, pois nesta, os pronomes interrogativos são pré-requisitos para ensinar a compreensão leitora. Portanto, concluiu-se que ele respondeu corretamente essas questões, por ter alcançado a compreensão do texto.

Durante o episódio no NAIALE, observou-se que antes da leitura, Clarice apresentou o livro aos alunos, disponibilizando-os para que pudessem manusear e entrar em contato com o objeto de leitura. Durante a leitura, ela optou por não interferir, preferindo deixá-los à vontade para que lessem, folheassem e observassem as gravuras do livro.

Em relação às estratégias utilizadas por Clarice após a leitura do livro "Ninguém gosta de mim", observamos que, devido Pedro e Ana terem lido muito rápido, Clarice interveio, explicando-Ihes que deveriam ler o texto pausadamente, procurando atentar para o significado do texto. Depois disso, ela formulou uma série de perguntas sobre a narrativa do livro aos alunos. A esse respeito, Cooper (1990) sugere que as seguintes perguntas podem contribuir para a construção do sentido de um texto narrativo, a saber: onde ocorre esta história? Quais são os personagens da história? Qual o título da história? - entre outras. É importante destacar que essas perguntas, “(...) podem variar, contanto que, elas continuem se referindo aos componentes essenciais do texto" (SOLÉ, 2009, p. 112).

Assim, de acordo com Solé (2009), podemos observar que, embora as perguntas feitas por Clarice tenham variado, todas se referiram aos componentes essenciais do texto, como por exemplo: Quem falou ninguém gosta de mim? Qual o título do livro? Qual o nome do cachorro? Ao mesmo tempo em que se referiram aos componentes essenciais do texto, algumas perguntas formuladas por Clarice foram perguntas de resposta literal e outras, perguntas para pensar e buscar, como é o caso da pergunta formulada por Clarice: Por que Coquinho estava entediado? - Observase, neste exemplo, que os alunos, apesar de terem recorrido ao texto, não conseguiram encontrar a resposta, e por isso, não responderam a essa pergunta. Segundo Trenche e Balieiro (2004, p. 180), "é importante sempre incentivar a criança a buscar no próprio texto suas dúvidas, mobilizar o que já sabe, o que pode ser construído por meio de outras leituras e conversas com o terapeuta". Esta penúltima pergunta formulada por Clarice vai ao encontro da afirmação de Trenche e Balieiro (2004), uma vez que, tendo observado que as crianças não encontraram, no texto, a resposta e, consequentemente, não responderam, Clarice interveio, conversando com as crianças, a fim de reduzir o espaço do significado da palavra que ainda era desconhecida, por meio da contextualização da situação 
A intervenção acima evidencia que a abordagem adotada, nas práticas do NAIALE, é a interacionista. Por meio dela, o texto deixa de ser usado como pretexto, para o ensino dos elementos gramaticais, e passa a ser objeto de ensino, no qual o aluno percebe o texto como uma construção do autor para atingir o interlocutor.

Quando o ensino de leitura segue essa direção, é comum que ocorra por meio de textos que estabeleçam alguma relação com as vivências, experiências e preocupações das crianças, os quais são retirados da escrita social, favorecendo a compreensão e consequentemente, um desempenho escolar satisfatório.

\section{Conclusão}

Este trabalho objetivou investigar a contribuição das práticas de leitura e compreensão de texto desenvolvida por profissionais da saúde, para o desempenho escolar do aluno surdo oralizado inserido no ensino regular.

A análise da prática de leitura e compreensão desenvolvida no NAIALE demonstrou que, esta, contribui para que o aluno surdo oralizado aprenda a ler, a compreender o texto escrito, atribua sentido à informação e consequentemente, tenha um desempenho escolar satisfatório, uma vez que, ocorre por meio de textos, de situações contextualizadas e do ensino sistemático dos elementos gramaticais - indispensáveis para leitura. A contribuição das práticas no NAIALE pode ser notada, durante a resolução dos exercícios pelo aluno surdo, sujeito desta pesquisa, mesmo àqueles nos quais apresentou dificuldade.

Queremos destacar que, embora tenha apresentado dificuldade, o desempenho escolar do aluno surdo oralizado, pode ser considerado satisfatório, o que revela a necessidade de uma maior interação entre as áreas da saúde-educação, por meio de políticas públicas que apontem para essa direção.

\section{Referências}

BOTELHO, P. Linguagem e letramento na educação dos surdos ideologias e práticas pedagógicas. Belo Horizonte: Autêntica, 2005.

BRASIL. Ministério da Educação. Secretaria de Educação Especial. Política Nacional de Educação Especial na Perspectiva da Educação Inclusiva. 
Documento elaborado pelo Grupo de Trabalho nomeado pela Portaria Ministerial $n^{\circ} .555$, de 5 de junho de 2007, prorrogada pela Portaria $n^{\circ} 948$, de 09 de outubro de 2007. Disponível em: <http://portal.mec.gov.br/seesp/ arquivos/pdf/politica.pdf>. Acesso em: 10 dez. 2010.

Ministério da Saúde. Portaria No 2.073/GM, de 28 de setembro de 2004, que institui a Política Nacional de Atenção à Saúde Auditiva, 2004. Disponível em: <http://dtr2001.saude.gov.br/sas/PORTARIAS/Port2004/GM/ GM-2073.htm>. Acesso em: 15 out. 2010.

CAGLIARI, L. C. Alfabetização e linguística. 2. ed. São Paulo: Scipione,1990.

COOPER, J. D. Cómo mejorar la comprensión lectora. Madrid: Aprendizaje/ Visor/MEC, 1990.

COLOMER, T; CAMPS, A. Ensinar a ler, ensinar a compreender. Porto Alegre: Artmed, 2002.

GÓES, M. C. R. Linguagem, surdez e educação. Campinas: Autores Associados, 1996.

LEMOS, A. M. O papel desempenhado pela língua de sinais nas estratégias de leitura do aluno surdo. 2007. 80f. Trabalho de Conclusão de Curso (Especialização em Língua Portuguesa) - Universidade Estadual do Ceará, 2007.

MENDES, B. C. A; NOVAES, C. Oficina de leitura com adolescentes surdos: uma proposta fonoaudiológica. In: BERBERIAN, A. P; MASSI, G. A; GUARINELLO, A. C. (Orgs.). Linguagem escrita - Referenciais para a Clínica Fonoaudiológica. São Paulo: Plexus, 2003.

OLIVEIRA, K. L; BORUCHOVITCH, E; SANTOS, A. A. A. Leitura e desempenho escolar em português e matemática no Ensino Fundamental. Paideia, [S. I.], v. 18, n. 41, p. 531-540, 2008.

PACCINI, V. L. R. Caminhos para uma prática inclusiva de leitura e escrita na escola. 2007. 177f. Dissertação (Mestrado em Educação) - Faculdade de Educação, Universidade Estadual Paulista, Marília, 2007.

PEREIRA, M. C. C. Leitura, escrita e surdez. 2. ed. São Paulo: FDE, 2009.

ROJO, R. Letramentos múltiplos, escola e inclusão social. São Paulo: Parábola, 2009. 
SACALOSKI, M. A inclusão social da pessoa com deficiência auditiva. In: XII Congresso Brasileiro de Fonoaudiologia. Foz do Iguaçu: Sociedade Brasileira de Fonoaudiologia, 2004.

SOLÉ, I. Estratégias de leitura. 6. ed. Porto Alegre: Artmed, 2009.

TRENCHE, M. C; BALIEIRO, C. R. A escrita e prática fonoaudiológica com crianças surdas/deficientes auditivas. Distúrbios da Comunicação, São Paulo, v.16, n. 2, 2004.

\author{
Notas \\ 1 Tendo em vista resguardar as identidades dos participantes, todos os nomes \\ utilizados nesse trabalho, são fictícios.
}

\title{
Correspondência
}

Lucineide Machado Pinheiro - Instituto Federal de Educação, Ciência e Tecnologia de São Paulo. Rua Pedro Vicente, 625, CEP: 01109-010 - Canindé, Sao Paulo, São Paulo, Brasil

E-mail: lucineidepinheiro@yahoo.com.br

Recebido em 25 de setembro de 2012

Aprovado em 26 de novembro de 2012 